\section{Schwangerschaftstest im Urin}

W. G. Guder

München, Deutschland

Synonym(e) Choriongonadotropintest im Urin; hCG-Test

Englischer Begriff gravidity test in urine; human chorionic gonadotropine test in urine

Definition Verfahren zum Nachweis von humanem Choriongonadotropin ( $\triangleright$ Choriongonadotropin, humanes) $>10 \mathrm{IE} / \mathrm{L}$.

Synthese - Verteilung - Abbau - Elimination Humanes Choriongonadotropin ( $\triangleright$ Choriongonadotropin, humanes) ist ein Glykoproteohomon mit einer Molmasse von 36-40 kDa, das wie die hypophysären Gonadotropine aus 2 Untereinheiten aufgebaut ist, von denen die $\alpha$-Einheit der des Lutropins $(\triangleright$ Luteinisierendes Hormon) gleich ist und die $\beta$-Kette spezifisch für CG ist. Es wird in den Synzytiotrophoblasten der Plazenta gebildet und in das mütterliche Blut abgegeben. Dort wird es in der freien Form in den Primärharn filtriert, bei der Rückresorption abgebaut und nicht resorbiertes Hormon im Urin ausgeschieden, wo es ab der ersten Woche nach Konzeption nachweisbar wird.
Funktion - Pathophysiologie $>$ Choriongonadotropin, humanes.

Analytik $>$ Choriongonadotropin, humanes.

Konventionelle Einheit Qualitativ als „,““ oder ,-““.

Referenzbereich - Frauen Negativ, ab 2. Woche nach Empfängnis positiv. Quantitative Werte im Plasma $\triangleright$ Choriongonadotropin, humanes

Indikation $>$ Choriongonadotropin, humanes.

Interpretation $>$ Choriongonadotropin, humanes.

Diagnostische Wertigkeit \ Choriongonadotropin, humanes.

\section{Literatur}

Stieber P, Schalhorn A (2009) Malignes Wachstum. In: Guder WG, Nolte J (Hrsg) Das Laborbuch in Klinik und Praxis, 2. Aufl. Elsevier/Urban und Fischer, München 